\title{
A Comparative Study of McDonald's Wedding Narratives with the Model of Anchoring
}

\author{
Mimi Huang \\ Humanities Department; Northumbria University, UK \\ E-mail: mimi.huang@northumbria.ac.uk
}

Doi:10.7575/aiac.alls.v.7n.6p.97

URL: http://dx.doi.org/10.7575/aiac.alls.v.7n.6p.97
Received: 10/08/2016

Accepted: 21/10/2016

\begin{abstract}
Fast-food giant McDonald's announced in 2010 that they would start hosting wedding ceremonies and receptions for couples who would like to get married in their restaurants in Hong Kong. This paper conducts a study comparing the differing representations of McDonald's wedding services through a narrative analytical approach. Specifically, this paper examines relevant discourses surrounding the launch of the corporation's wedding services from the British media (e.g. Daily Mail, the Independent) as well as public discourses in Hong Kong (e.g. McDonald's Hong Kong website, and CNN's Hong Kong news). It is found that these narratives have a significant degree of discrepancy in depicting McDonald's wedding stories. These differences further raise the question of how differing narrative strategies are employed to conceptualise the brand's emergent wedding narratives in a unique social-cultural environment. In the discussion of McDonald's wedding stories, the focus is placed on the cognitive and linguistic aspects of the discourse. An analytical model of "anchoring" will be proposed and applied to investigate the cooperation's marketing strategies as well as the media's reaction towards such promotions. It is argued that a narrative can promote or demote a brand's identity and position through the process of anchoring. It is further argued that anchoring is an important cognitivepsychological strategy in conceptualization and meaning construction.
\end{abstract}

Keywords: narrative inquiry, cognitive narratology, anchors, anchoring, meaning construction

\section{Introduction}

On the First of January, 2011, three McDonald's branches in Hong Kong launched their on-site wedding services, becoming the first place in the world where the fast-food chain regularly holds wedding ceremonies and receptions. Detailed information and regular updates of McDonald's wedding packages are available on the company's Hong Kong website. McDonald's wedding promotion has attracted media attention around the globe, creating an emergent body of discourses that narrate McDonald's wedding stories.

Although related in terms of topic, these stories vary in their content, attitudes and ideologies. This paper will explore these differences by examining four narratives in response to McDonald's launch of their wedding services. Two of these narratives are from the British media, with one published by the Independent and the other by the Daily Mail. The third story is reported by CNN's Hong Kong branch, and the fourth story is featured on McDonald's official website in Hong Kong. Each story has its own unique social and cultural context, and each has a distinct voice in the telling of the wedding stories. Most importantly, the reading of each story calls for a series of cognitive and linguistic processes that contribute to the reader's interpretation of McDonald's wedding promotion. In order to investigate the cognitivenarratological strategies employed in these texts, an analytical model of anchoring will be proposed and applied to the discussion of the reader's meaning construction process when reading the wedding narratives.

\section{Analytical approaches}

Before the analysis of the selected narratives, I shall first provide a brief review of the mainstream approaches to analysing corporate and media discourses, and introduce recent developments in the field. The analytical approach adopted in this paper is cognitive narratology, which will be reviewed in section 2.2. Following this I shall propose a model of anchoring for analyzing narrative discourse. It will be argued that this analytical model will serve as a valuable contribution to the discussion of discourses in varying cultural contexts.

\subsection{A brief review of analytical approaches to corporate and media discourses}

When corporate and media discourse is under scrutiny, issues such as "power", "ideology", "identity" and "position" are of particular importance. One discipline that studies these issues systematically is critical discourse analysis, hereafter referred to as CDA (Fairclough 2001, van Dijk 2008). In relation to CDA, sociology, management studies and organizational scholarship also provide in-depth discussions of corporate discourses, with research focuses on corporate strategies, developments and positioning (Groucutt 2006, Bloom \& Cedestrom 2009, Yolles et al., 2011). Global brands and corporations are often the research subject, one prime example being the fast food brand McDonald's (Boje 2008, Ritzer 2011) The term "McDonaldization" (Ritzer 1998, 2010) has been established to refer to a wide range of social, 
cultural and political phenomena around the globe that have been influenced by the development of the brand.

Apart from the aforementioned approaches, recent studies in narrative inquiry have made important contributions to the examination of corporate and media discourses (Lightfoot \& Daiute 2004, Herman 2009, Clandinin \& Huber 2010). The chief concern of narrative inquiry is a story's "meaning making" aspects, which include the linguistic, cognitive and psychological dimensions of a narrative, as well as its social, political and cultural context. Corporate discourses in this regard are considered as stories that narrate the corporate identity, developments and positions in a society and culture. One major area in narrative inquiry is cognitive narratology, which examines the cognitive aspect of a story with the focus on relevant linguistic strategies. I shall argue in the following section that cognitive narratology will serve as a useful tool when analyzing McDonald's wedding narratives.

\subsection{A review of cognitive narratology}

Situated within the broader field of narrative studies, cognitive narratology takes a postclassical approach to discourses (Herman 2009). Influenced by the "cognitive turn" that took place in the second half of the 20th century, cognitive narratology connects closely with cognitive science and empirical psychology, whilst still thoroughly examining the textual features of a discourse.

One important claim of cognitive narratology is that narratives function as a way of thinking and communicating (Ryan 2010, p.476). This claim represents a constructivist viewpoint that sees cognitive processes as channeling, correlating and evaluating external stimuli in respect of what we already know, i.e. what is stored in our encyclopedic knowledge (Jahn 2005: 68). In this light, if stories are conceptualised as having a strong connection with a context that is familiar to the reader, they are more likely to be identified by the reader as real, acceptable and even desirable. Using McDonald's wedding discourse as an example, the emphasised linguistic expressions such as "wedding parties", "engagement parties" and "anniversary celebrations" on the company's Hong Kong website (2011 a) can activate the reader's familiar schemas of weddings and wedding related activities, and hence inviting the reader to consider a "McDonald's wedding party" to be part of the broader wedding scenario.

For a newly emergent corporate storyline to be successful, it is of vital importance to promote such cognitive-linguistic pairings in order to enhance the conceptual status of the story in the reader's perception. It should be noted that these cognitive-linguistic pairings can also work against a newly emergent storyline when the storyteller's intention is to criticise or undermine the story. Take the Daily Mail's narrative for example (2010b), the term "McWedding" in the headline may trigger a number of arguably derogatory terms (e.g. McJob, McFuture) with which the reader may associate the brand.

Associations between linguistic expressions and their conceptual counterparts can therefore make significant contributions to the reader's interpretation and reception of a story. In order to investigate these associations, I shall in the following section propose a model based upon the notion of anchoring. This model of anchoring will then be applied to analyse the four narratives in relation to McDonald's wedding stories.

\subsection{A model of anchoring for narrative analysis}

In this section, I shall introduce the notion of anchoring, which is arguably one of the most fundamental cognitive strategies that we employ when processing incoming data in everyday situations. The term "anchor" has received varying definitions in differing disciplines. In social psychology, "anchoring" refers to a cognitive procedure whereby the understanding of a new phenomenon is associated with existing social objects (Slunecko, Hengl 2007). In a compatible fashion, Hutchins (2005) defines "anchoring" as a reasoning process that employs a material structure in order to stabilise its association with a conceptual structure. In cognitive narratology, Dancygier (2007), has also discussed a type of "narrative anchors" that serve as place holders for emergent mental spaces in a given discourse.

In this paper, the meaning of anchor is largely compatible with the above mentioned notions. More specifically, the term highlights the cognitive-linguistic interface in meaning processing. This notion of an anchor is multimodal in nature, and is grounded in one's encyclopaedic knowledge. The concept of anchoring accords to the main claim of cognitive narratology reviewed previously, and can reveal significant information of meaning construction, ideology and identity as communicated in a discourse. In this view, an anchor needs to be a symbolic assembly, or a formmeaning pairing (Langacker 1987, Croft \& Cruse, 2004) The types of form are multi-model, including written forms, signs, symbols, sounds, etc.; although in this paper, I mainly focus on the form of written texts. For instance, the symbolic assembly of wedding-WEDDING means the linguistic form of "wedding" is paired with the conceptual entity WEDDING in the reader's encyclopaedic knowledge.

For a symbolic assembly to function as an anchor in a discourse, it needs to act as a stimulus that calls forth an associated informational context. Consequently, "anchoring" is defined as the process of establishing an association between a stimulus and an informational context. As specified in the definition, an anchor must have a pre-existing association with the target entity. The term "informational context" may refer to a specific conceptual entity (e.g. WEDDING), or a particular schema (e.g. WEDDING CEREMONIES), or an overarching storyline (e.g. WEDDINGS ARE FORMAL SOCIAL ACTIVITIES HELD IN RESPECTABLE SOCIAL VENUES).

In the model of anchoring, a linguistic expression in a given discourse functions as a prompt for its conceptual counterpart, which, if previously associated with an informational context, will activate the target entity in the reader's cognitive process, and consequently promoting the activation status of the target entity in the reader's consciousness. Given anchors are multimodal in nature, and operate upon one's encyclopedic knowledge; the process of anchoring is 
also likely to activate relevant affective processes. In the context of McDonald's wedding services, if the story is to promote the concept of "McDonald's weddings" in the reader's awareness, one effective strategy would be to establish the association between the concept of MCDONALD'S and the target entity of WEDDINGS. Furthermore, if the reader generally has a positive affect towards the concept of WEDDINGS, then this positive affect is likely to be transferred to MCDONALD'S as well through the process of anchoring. However, if the story communicates a negative affect toward McDonald's wedding services, this negative affect may be attached to this newly established anchor and its associated entities.

In order to illustrate the working of the anchoring model, I shall use the headline from the Independent's narrative (2010a) as an example:

(1) McDonald's to make wedding cakes.

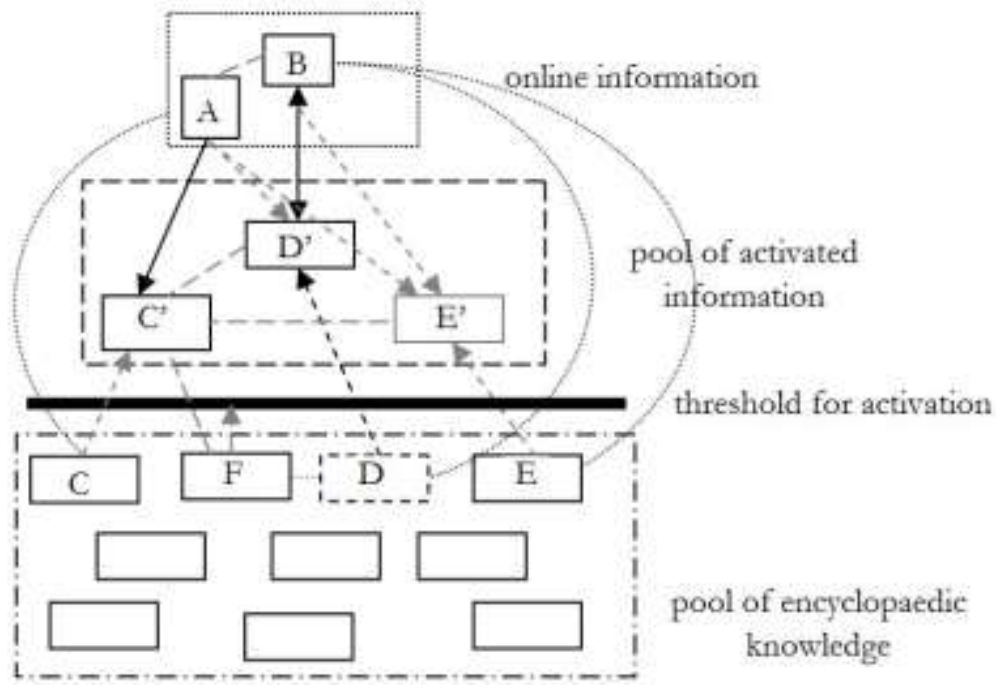

Figure 1. A model of anchoring in narrative interpretation

(Illustration keys: A= McDonald's; B=WEDDING CAKES; C=FAST FOOD; D=WEDDINGS; E=RECEPTIONS; $\mathrm{F}=$ COUPLES)

Example (1) is the title of the Independent's story of McDonald's wedding services. Figure 1 outlines the function of anchors when Utterance (1) is processed by the reader. The illustration keys explain the representation of entities by letters. The bottom box in the figure is the "pool of encyclopedic knowledge", which stores the reader's previously acquired information and knowledge. The box in the middle is the "pool of activated information", which accommodates the information that is currently active in the reader's consciousness. For an entity to be active, it would need to be activated from the "pool of encyclopedic knowledge", and to rise above the "threshold for activation" (which is represented by the solid bar between the two pools, hereafter referred to as TfA), and enters the "pool of activated information". One way to activate a given entity is through the process of anchoring, where a symbolic-assembly becomes part of the online information (which is represented by the top box in Figure 1). If the process of anchoring is successful in a given discourse, initially activated entities are likely to remain active in the ongoing discourse, and are likely to enhance the status of activation of their related entities too. When one anchor is connected to another anchor, a process of "anchor chaining" can take place, which will further enhance the activated status of target entities in the reader's information processing.

According to the explanations above, when Utterance (1) is processed by the reader, the symbolic-assemblies of A (i.e. McDonald's-MCDONALD'S) and B (i.e. wedding cakes-WEDDING CAKES) become part of the "online information". Suppose A has a pre-existing association with C (i.e. FAST FOOD), and B is associated with D (i.e. WEDDINGS) and E (i.e. RECEPTIONS). Through the process of anchoring, these entities will be activated, rise above TfA, and enter into the reader's conscious processing (i.e. These entities are now represented as C', D' and E' respectively in the "pool of activated information").

With the above anchoring model, example (1) may be interpreted with three possible outcomes. The first possibility assumes the Independent's narrative is to promote McDonald's newly emerged identity in Hong Kong's wedding market, and is to encourage the reader to establish a new conceptual association between A and B (i.e. to associate MCDONALD'S with WEDDINGS). In order to achieve this, the narrative will need to connect C' with D' and E'. In other words, the story will need to persuade the reader to consider FAST FOOD to be desirable for WEDDINGS and RECEPTIONS. If such connection is successful, a potential anchor between MCDONALD'S and WEDDING may be established in the narrative. This anchoring effect may also facilitate the activation status of entity F (i.e. COUPLES), connecting the concept with MCDONALD'S and FAST FOOD. Therefore, in a context where McDonald's is positioned as an uprising supplier of wedding services, the concept of MCDONALD'S will serve as a new anchor for WEDDINGS and its related entities, hence establishing an emergent identity for the brand in Hong Kong's wedding market. 
Furthermore, if this association is consolidated, further anchoring effect between COUPLES and MCDONALD'S may be subsequently established, creating a chain of anchors that associate MCDONALD'S with other aspects in a couple's relationship, some of which may be ENGAGEMENT, WEDDING and ANNIVERSARY. In terms of the affective aspect, if the reader holds positive attitudes towards WEDDINGS and its relevant entities (e.g. ENGAGEMENTS, ANNIVERSARY, RECEPTIONS), these positive attitudes are likely to be attached to the entities of MCDONALD'S and FAST FOOD. Thus the reader is more likely to find McDonald's wedding services acceptable and even desirable.

The second possible interpretation takes an opposite position, and assumes the Independent's narrative is to discourage the above processes of anchoring and anchor chaining. In this situation, the story is likely to make less positive connections between FAST FOOD and WEDDINGS. Consequently, the association between MCDONALD'S and WEDDINGS is likely to be kept minimal, and the subsequent connection between MCDONALD'S and COUPLES is unlikely to be established. In addition, attitudes and emotions attached to the entity of WEDDINGS will not have a direct influence on the entity of MCDONALD'S or FAST FOOD as no anchoring effect takes place in the story. The reader will subsequently interpret McDonald's wedding story without a significant change of attitudes or emotions towards the concepts involved.

Finally, the third possible outcome supposes that the Independent's narrative encourages the association between MCDONALD'S and WEDDINGS, as well as the connection between MCDONALD'S and COUPLES. Unlike the first outcome, however, the story introduces a less positive affect towards MCDONALD'S and FAST FOOD. Through the process of anchoring, this negative affect can transfer to the entities of WEDDINGS and COUPLES. As a result, the reader may have less positive attitudes towards people who hold their wedding ceremonies and receptions at McDonald's.

The analysis of Example one illustrates an initial account of meaning construction and communication through the model of anchoring. Following this the next step will be to analyse and compare the process of interpretation and meaning construction in the four narratives.

When identifying the key anchors in each narrative, I am going to adopt the method of corpus linguistics (Stubs 1996, Glynn \& Fischer 2010) to aid my discussion of the anchoring effect. One way to study key anchors is by locating their linguistic counterparts, i.e. key words in the texts. In corpus linguistics, key words in a given text can be identified by the use of a reference corpus (in this case, the British National Corpus, hereafter as BNC) that provides background information for the target texts. In this paper, WordSmith Tools @) was employed to compile a list of keywords in each narrative according to the keyness value. "Keyness" adopted in this study represents relatively high frequencies of words in the target text as compared to their frequencies in a reference corpus (in this case, the BNC). For detailed discussions of keyness value and its examination in corpus linguistics, see Scott (1997), and Scott \& Tribble (2006).

\section{Discussions of McDonald's wedding narratives}

In this section, four narratives are to be discussed in terms of their representation of McDonald's wedding services (See Table 1). These four narratives are selected because they focus on the same corporate event but represent varying voices from diverse contexts. Elements of diversity include broadsheets, tabloid, regional news, international news, media reports and corporate featured article. The Independent and the Mail Online are two major newspapers in the UK covering a wide range of readership, with the former being regarded as broadsheet and the former generally regarded as tabloid (Keeble 2006). The two articles selected from the Independent (2010a; hereafter referred to as "Independent") and the Mail Online (2010b; hereafter referred to as "Mail Online") were written in 2010, just before McDonald's launched their wedding services. CNNGO is a web-based newspaper with a regional staff separate from CNN's home division, providing regional news to the local reader. CNNGO Hong Kong positions itself as a local newspaper reporting local news to Hong Kong viewers. The article tells the story of McDonald's first engagement party after they started the wedding services in January 2011 (2011b; hereafter referred to as "CNNGO HK"). The same event was narrated in an article published on McDonald's Hong Kong website, which is the fourth narrative (2011a; hereafter referred to as "McDonald's") selected for the discussion.

Table 1. Four McDonald's wedding narratives

\begin{tabular}{lll}
\hline Narratives & Title & Length \\
\hline McDonald's & McDonald's wedding party services make public debut & 557 \\
\hline CNNGO HK & $\begin{array}{l}\text { Will you McMarry me? Couple opt for McDonald's engagement } \\
\text { party }\end{array}$ & 378 \\
\hline Mail Online & $\begin{array}{l}\text { The McWedding: Couples set to tie knot in fast food chain } \\
\text { branches from January }\end{array}$ & 363 \\
\hline Independent & McDonald's to make wedding cakes & 231 \\
\hline
\end{tabular}

The analysis of the narratives consists of three steps. Step One is to examine the key anchors (i.e. the key symbolic assemblies) that the reader is likely to identify when reading the narratives. These key anchors, once identified, will trigger anchored concepts to be processed in the discourse. Step Two is to investigate how these anchored concepts function in each narrative. Step Three further discusses if the narratives encourage any new anchoring relationships to emerge in the stories. 
To start with, the key anchors in each narrative will be identified through their linguistic counterparts that score a high score of keyness value when set against BNC as the reference corpus. Table 2 below shows the top 5 keywords in the narratives, each ranked from top to bottom with a descending keyness value. Amongst the key words, "McDonald's" appears in all narratives, and "wedding" (or "engagement") is the second most frequent keyword. The other key words are either related to the fast-food brand and its Hong Kong branches (e.g. "McWedding", "Hong Kong"), or are closely associated with the concept of WEDDING (e.g. "party", "couple", "cakes"; "Tse" and "Kwong" are the surnames of the wedding couple). It can therefore be argued that the entities of MCDONALD'S and WEDDING are likely to function as key anchors in the narratives. As illustrated in Figure 1, these two anchors will appear in the area of "online information" in the reader's discourse processing.

Table 2. Key words list of the four narratives

\begin{tabular}{|c|c|c|c|c|c|c|}
\hline Narrative & $\mathrm{N}$ & Key word & Freq. & $\%$ & RC. Freq. & Keyness \\
\hline \multirow[t]{5}{*}{ McDonald's } & 1 & MCDONALD'S & 13 & 2.23 & 203 & 215.3 \\
\hline & 2 & WEDDING & 16 & 2.75 & 3218 & 184.24 \\
\hline & 3 & PARTY & 16 & 2.75 & 37720 & 105.94 \\
\hline & 4 & MCDONALD & 6 & 1.03 & 297 & 85.71 \\
\hline & 5 & ENGAGEMENT & 6 & 1.03 & 1209 & 68.96 \\
\hline \multirow{5}{*}{$\begin{array}{l}\text { CNNGO } \\
\mathrm{HK}\end{array}$} & 1 & MCDONALD'S & 8 & 2.04 & 203 & 131.22 \\
\hline & 2 & KWONG & 5 & 1.28 & 2 & 116.13 \\
\hline & 3 & TSE & 5 & 1.28 & 17 & 100.92 \\
\hline & 4 & ENGAGEMENT & 7 & 1.79 & 1209 & 88.19 \\
\hline & 5 & PARTY & 11 & 2.81 & 37729 & 73.29 \\
\hline \multirow[t]{5}{*}{ Mail Online } & 1 & MCDONALD'S & 6 & 1.63 & 203 & 95.72 \\
\hline & 2 & MCWEDDING & 2 & 0.54 & 0 & 50.03 \\
\hline & 3 & WEDDING & 4 & 1.08 & 3218 & 38.58 \\
\hline & 4 & HONG KONG & 3 & 0.81 & 2601 & 28.48 \\
\hline & 5 & COUPLE & 4 & 1.08 & 11649 & 28.35 \\
\hline \multirow[t]{4}{*}{ Independent } & 1 & WEDDING & 7 & 2.87 & 3218 & 81.23 \\
\hline & 2 & MCDONALD'S & 3 & 1.23 & 203 & 46.22 \\
\hline & 3 & CAKES & 3 & 1.23 & 953 & 36.98 \\
\hline & 4 & HONG KONG & 3 & 1.23 & 2815 & 30.49 \\
\hline
\end{tabular}

With the key anchors identified, the second analytical step is to investigate the anchors' associated informational contexts, which are likely to be processed in the reader's "pool of activated information" in the reading process. One approach to investigate an anchor's associated entities is to examine the collocation of the linguistic anchor in a reference corpus. In the current discussion, entities with established associations with MCDONALD'S and WEDDINGS are likely to be collocates of "McDonald's" and "wedding" / "weddings" in a reference corpus such as BNC. Adopting the corpus linguistics approach, WordSmith Tools (C) was used to identify the top 100 content words within BNC that occur within five words to the left or right of the words of "McDonald's" and "wedding" / "weddings" respectively. All collocated words have a mutual relationship (MI) above three with the target words, indicating a relatively strong collocation. These collocates were then searched within each narrative for their frequency. Table 3 below illustrates the results. The number quoted in brackets indicates the frequency of each collocate in the narrative. The columns "NoC1" and "NoC2" calculate the number of collocates, with the former associated with "wedding" or "weddings" in BNC, and the latter associated with "McDonald's". As revealed in Table 2, the entities of WEDDINGS and MCDONALDS each have their own anchored informational contexts. Whilst WEDDINGS tend to be associated with the social aspects of weddings, celebrations and people involved, the entity of MCDONALD'S tends to trigger informational contexts of the fast food culture, and the types of food served in a fast-food restaurant (e.g. BURGER, FRIES, and MCNUGGETS). 
Table 3. Collocates of key words in the four narratives

\begin{tabular}{|c|c|c|c|c|}
\hline Narratives & $\begin{array}{l}\text { Collocates with "wedding" / } \\
\text { "weddings" }\end{array}$ & $\begin{array}{l}\text { NoC } \\
1\end{array}$ & $\begin{array}{l}\text { Collocates } \\
\text { "McDonald's" }\end{array}$ & $\mathrm{NoC} 2$ \\
\hline McDonald's & $\begin{array}{l}\text { anniversary (2); bouquet (1); cake } \\
\text { (1); celebration (1); ceremonies (1); } \\
\text { couples (2); day (3); engagement (6); } \\
\text { gifts (1); golden (1); gown (1); guests } \\
\text { (4); invitation (1); rings (2); venue } \\
\text { (2); }\end{array}$ & 15 & $\begin{array}{l}\text { food (2); limited (1); quality } \\
\text { (1); restaurant (3); restaurants } \\
\text { (1); surprise (1) }\end{array}$ & 6 \\
\hline CNNGO HK & $\begin{array}{l}\text { bouquet (1); day (2); engagement } \\
\text { (7); guests (1); groom (2); rings (2) }\end{array}$ & 6 & $\begin{array}{l}\text { burger (1); chain (1); Chinese } \\
\text { (1); food (1); fast (1); French } \\
\text { fry (1); fries (1); restaurant } \\
\text { (1); surprise (2) }\end{array}$ & 9 \\
\hline Mail Online & $\begin{array}{l}\text { anniversary (1); bride (2); cake (1); } \\
\text { celebrate (1); ceremony (2); couples } \\
(2) \text {; dress (1); reception (2) }\end{array}$ & 8 & $\begin{array}{l}\text { banned (1); chain (3); chicken } \\
\text { (1); expect (1) fast (2); food } \\
\text { (2); fries (1); MAC (1); } \\
\text { Mcnuggets (1); restaurant (3) }\end{array}$ & 10 \\
\hline Independent & $\begin{array}{l}\text { attend (1); cake(w) (5); gifts (1); } \\
\text { guests (1); }\end{array}$ & 4 & $\begin{array}{l}\text { burger (1); chains (1); fast (1); } \\
\text { food (1); French fries (1); fries } \\
\text { (1); restaurant (1) }\end{array}$ & 7 \\
\hline
\end{tabular}

In the third analytical step, I shall consider if any changes in these pre-existing associations are preserved or modified in the narratives. Interestingly, in terms of the frequencies of the anchored entities, McDonald's narrative has employed the most anchored entities of WEDDINGS (i.e. 15 in NoC1), and the least anchored entities of MCDONALD'S (i.e. 6 in NoC2). In other words, the McDonald's narrative "tones down" its existing anchored concepts, and highlights a strong emergent connection between MCDONALD'S and a range of associated concepts of WEDDINGS. Take Example (2) below for instance:

(2) The basic package costs HKD\$9,999, which covers invitation cards, venue rental, food, gifts for the couple and their guests, basic venue decoration, special games, audio system usage and Master of Ceremonies service. (2011a)

In Example (2) alone, McDonald's narrative has adopted seven linguistic expressions (as italicised in the example) that are traditional collocates to the concept of WEDDINGS. With such a strong informational context in place, the narrative clearly encourages the reader to establish a new anchoring relationship between MCDONALD'S and that of WEDDINGS. Referring to the claim in cognitive narratology that narrations are ways of conceptualizing the reality, the meaning communicated in McDonald's narrative can be paraphrased as "think weddings, think McDonald's". This new anchoring relationship between MCDONALD'S and WEDDINGS also represents an emergent identity of the brand, who positions itself as an uprising competitor in Hong Kong's wedding market. Furthermore, in the aspect of attitudes and emotions, because the informational contexts of WEDDINGS and CELEBRATIONS are significantly foregrounded, if the reader has generally positive attitudes and emotions towards these concepts and schemas, the relevant attitudes and emotions are likely to be transferred to the reader's conceptualization of the entity of MCDONALD'S as well. Given this is McDonald's own promotion of their wedding services, the above narrative strategies will achieve desirable interpretive results for the corporation.

In comparison to McDonald's story, the narratives of Mail Online and CNNGO HK posit a reasonably balanced display of existing anchored concepts of MCDONALD'S and WEDDINGS (e.g. with 6 and 8 in NOC1 and 9 and 10 in NOC2 respectively). One possible result of balancing the two informational contexts is that whilst the connection between MCDONALD'S and WEDDINGS may to some extent be enhanced in the discourse, the existing anchored contexts that depict McDonald's as a fast-food chain remain salient and unchallenged.

(3) Imagine having your ceremony, reception, wedding cake and catering for up to 100 people provided for just $£ 250$. There's just one drawback - it's at McDonald's (Mail Online 2010b)

(4) "Will you Mcmarry me? I promise to always let you have the last French fry." (CNNGO HK 2011b)

Although examples (3) and (4) have employed linguistic expressions that can trigger anchored concepts of WEDDINGS (i.e. "ceremony", "reception" and "marry"), the informational context of MCDONALD'S is equally strong (i.e. "McDonald's", and "French fry", 'Mcmarry"). Readers of these two narratives may recognise McDonald's new position in Hong Kong's wedding market, but they will also be reminded of the brand's existing tradition as a fast-food chain. Also, the balanced anchoring effects between the two existing information contexts would suggest the readers' attitudes towards McDonald's are unlikely to be greatly influenced by their attitudes towards the concepts of weddings and celebrations.

Finally, the Independent's narrative illustrates an even weaker connection between the two key entities. Whilst McDonald's excising informational context remains reasonably strong in the narrative (e.g. 7 in NOC2), the brand's emergent identity as a possible anchor to the concept of WEDDING is kept to minimum (e.g. 4 in NOC1). The title of 
the narrative -- "McDonald's to make wedding cakes" (2010a) - as analysed in example one, encourages the reader to consider the wedding stories as add-on features to the fast-food chain, instead of the brand's newly emergent identity. Similar to the narratives of Mail Online and CNNGO HK, the Independent's story does not channel significant changes to the reader in the affective aspect.

The above discussion analyses the process of meaning construction in the four selected narratives. The model of anchoring has provided useful insights of how each narrative employs relevant strategies in order to trigger a purposeful informational context that either enhances existing associations or promotes emergent associations between key entities. The analytical results have shown that whilst McDonald's narrative primes for a newly established anchoring relationship between MCDONALD'S and WEDDINGS, the media reception in both UK and Hong Kong adopts a more neutral strategy in maintaining existing anchors and their associated informational contexts.

\section{Conclusion}

This paper has discussed the representation of McDonald's launch of wedding services in four selected narratives. The analysis of McDonald's wedding story has shown the dynamic relationship between conceptual entities and informational contexts when an emergent corporate identity is proposed and reviewed in a culturally-enriched discourse.

A model of anchoring within the field of cognitive narratology has been proposed and applied in this paper to analyse the meaning construction in the selected narratives. Attention has been paid to the narratives' linguistic, cognitive and psychological dimensions. The model of anchoring reveals the cognitive and linguistic processes that operate upon the reader's encyclopedic knowledge when conceptualizing and evaluating particular social and cultural phenomena. The analytical results demonstrate that the anchoring process and anchoring effect are important cognitive strategies for communication.

\section{References}

Anonymous.(2010a). Mcdonald's to Make Wedding Cakes. The Independent. URL: http://www.independent.co.uk/lifestyle/food-and-drink/mcdonalds-to-make-wedding-cakes-2105652.html?origin=internalSearch [01/06/2016]

Anonymous. (2010b). The Mcwedding: Couples Set to Tie Knot in Fast Food Chain Branches from January. Mail Online. URL: http://www.dailymail.co.uk/news/article-1320488/McDonalds-wedding-Couples-marry-fast-food-chainHK-January.html [01/06/2016]

Anonymous. (2011a). Mcdonald's Wedding Party Services Make Public Debut. McDonald's Corporation. URL: http://mail.mcdonalds.com.hk/english/about/press/press.asp?id=110214 [01/06/2016]

Anonymous. (2011b). Will You Mcmarry Me? Couple Opt for Mcdonald's Engagement Party. CNN Go Hong Kong Essentials. URL: http://www.cnngo.com/hong-kong/life/mcengagement-party-valentines-day-033103 [01/06/2016]

Bloom P., \& Cederstrom C. (2009). The Sky's the Limit: Fantasy in the Age of Market Rationality. Journal of Organizational Change Management 25(2), 159 - 180. http://dx.doi.org/10.1108/09534810910947190

Boje D. M. (2008). Storytelling Organizations. Los Angeles, London: SAGE.

Clandinin D. J., \& Huber J. (2010). Narrative Inquiry. In P. Peterson, E. Baker \& B. McCGaw (Eds.), International Encyclopedia of Education (3rd ed.) (pp.436-441). New York: Elsevier Science.

Croft, W. \& Cruse, D. A. (2004) Cognitive Linguistics. Cambridge: Cmbridge Univesity Press.

Dancygier B. (2007). Narrative Anchors and the Processes of Story Construction. Style 41(2), $133-152$. http://www.jstor.org/stable/10.5325/style.41.2.133

Fairclough N. (2001). Language and Power (2nd ed.). Harlow, Eng, New York: Longman.

Glynn D., \& Fischer K. (2010). Quantitative Methods in Cognitive Semantics: Corpus-Driven Approaches. Berlin, New York: De Gruyter Mouton.

Groucutt J. (2006). The Life, Death and Resuscitation of Brands. Handbook of business strategy 7, $101-106$. http://dx.doi.org/10.1108/10775730610618693

Herman D. (2009). Cognitive Approaches to Narrative Analysis. In J. Vandaele, G. Brône (Eds)., Cognitive Poetics: Goals, Gains and Gaps (pp.79-118). Berlin, New York: Mouton de Gruyter.

Hutchins E. (2005). Material Anchors for Conceptual Blends. Journal of Pragmatics 37, 1555-1577. doi:10.1016/j.pragma.2004.06.008

Jahn M. (2005). Cognitive Narratology. In D. Herman, M. Jahn, M. L. Ryan (Eds.), Routledge Encyclopedia of Narrative Theory (pp. 69-71). London: Routledge.

Keeble R. (2006). The Newspapers Handbook (4th ed.). London; New York: Routledge.

Langacker R., W. (1987). Foundations of Cognitive Grammar, Vol.1:Theoretical Prerequisites. Stanford: University of Stanford Press.

Lightfoot C. \& Daiute C. (Eds). (2004). Narrative Analysis: Studying the Development of Individuals in Society. Thousand Oaks, Calif: Sage. 
Ritzer G. (1998). The Mcdonaldization Thesis : Explorations and Extensions. London: Sage.

Ritzer G. (2010). Mcdonaldization: The Reader (3rd ed.). Thousand Oaks: Pine Forge Press.

Ritzer G. (2011). The Mcdonaldization of Society, (6th ed.). Thousand Oaks, Calif; London: Pine Forge.

Ryan M. L. (2010). Narratology and Cognitive Science: A Problematic Relation. Style 44(4), 469-495. http://www.jstor.org/stable/10.5325/style.44.4.469

Scott M. (1997). PC Analysis of Key Words - and Key Key Words. System 25, 233-245. doi:10.1016/S0346251X(97)00011-0

Scott M., \& Tribble C. (2006). Textual Patterns. Amsterdam: John Benjamins.

Slunecko T. \& Hengl S. (2007). Language, Cognition Subjectivity: A Dynamic Constitution. In J. Valsiner, A. Rosa (Eds.). The Cambridge Handbook of Social-Cultural Psychology (pp. 44-61). Cambridge: Cambridge University Press.

Stubbs M. (1996). Text and Corpus Analysis: Computer-Assisted Studies of Language and Cutlure. Oxford: Blackwell. van Dijk T. A. (2008). Discourse and Power. Basingstoke: Palgrave Macmillan.

Yolles M., Fink G. \& Dauber D. (2011). Organisations as Emergent Normative Personalities: Part 1, the Concepts. Kybernetes 40(5), 635 - 669. http://dx.doi.org/10.1108/03684921111142223 